\title{
Analysis of Common Clinical Practice Teaching Methods in Medical Colleges and Universities
}

\author{
Diansong Yang, Yanxia Chi*, Huiping Liu, Dongmei Li \\ Jiamusi University, Jiamusi 154000, Heilongjiang Province, China \\ *Corresponding author: Yanxia Chi, yanxiachi123@163.com
}

\begin{abstract}
Clinical practice teaching is an important part of medical education. For medical students in colleges and universities, the teaching method is mostly single before the teaching reform. Innovative clinical practice teaching methods have been implemented in colleges and universities with the deepening of the teaching reform in recent years.
\end{abstract}

Keywords: Teaching method; Clinical practice; Medical student training

Publication date: December 2021; Online publication: December 23, 2021

\section{Introduction}

Based on the overall goal of medical education, clinical practice teaching is a paradigm formed by combining teaching elements related to clinical practice in a scientific way, with the purpose to promote the consolidation of students' medical knowledge and clinical skills ${ }^{[1]}$. As one of the important links in medical education, clinical practice teaching plays a very important role in cultivating high-quality healthcare personnel. The teaching method used by medical colleges and universities in China, which mainly learnt and drew lessons from the former Soviet Union, was formed in the early 1950s. The training objectives of medical students are relatively general and single. In recent years, with the reform of clinical practice teaching in China, a variety of teaching methods have emerged one after another, improving the quality of teaching through the exploration and optimization of the new teaching model.

\section{Teaching methods based on the principle of evidence-based medicine (EBM)}

EBM is an emerging discipline and medical model which developed rapidly in the 1990s. EBM is the knowledge of medical practice based on evidence, specifically, the best available evidence while taking into account of the amount of existing resources, the needs and value orientation of people, as well as the science of medical practice. The introduction of EBM into clinical practice is an inevitable trend in the development of clinical medicine, which is conducive to the cultivation of qualified doctors with comprehensive abilities, innovative skills, and other humanistic qualities. There is evidence that through the introduction of evidence-based clinical practice models in medical practice - ward rounds, case discussions, and consultations - the performance of clinicians and the quality of medical care have shown improvements along with a reduction in medical expenses ${ }^{[2]}$. EBM-oriented teaching methods such as PBL and CBL have been gradually developing in China, and with their implementations, remarkable results have been achieved.

\subsection{Problem-based learning (PBL)}

In 1969, Howard Barrows, a professor of neurology at McMaster University School of Medicine in Canada, 
proposed the PBL teaching model based on information processing psychology and cognitive psychology. This approach attempts to merge self-directed learning and teacher guidance; it is a patient-led, problembased, student-centered, and teacher-oriented interactive learning method. The PBL teaching model developed rapidly, and more than 1,700 medical schools around the world have been implementing the teaching method, which has become the mainstream of modern medical education reform. Previously, lectures were widely held for medical students in China, taking the teacher as the main body, and the students as the center of education. Basic theoretical knowledge can be explained systematically, but students are in a state of passive acceptance of knowledge; there is relatively less interaction in classrooms using the lecture method, which hinders students' subjective initiative and the cultivation of their clinical thinking skills. In recent years, some medical schools in China have implemented the PBL teaching method in clinical practice teaching and have shown positive results ${ }^{[3,4]}$. A number of scholars have organically combined the PDCA cycle teaching method with the PBL teaching method, which have also led to some positive results ${ }^{[5,6]}$. Certainly, with the popularization of PBL, problems have also surfaced in its practical application, such as inadequate case preparation, difficulty in identifying problems, perplexity in grasping certain points, and so on ${ }^{[7]}$.

\subsection{Case-based learning (CBL)}

CBL developed from PBL. It is a group discussion teaching method based on clinical cases with relevant questions, which guide and inspire students to discuss around the problems. Compared with PBL, CBL allows students to learn about a certain subject before the actual class; it guides students to explore, discover, and solve problems gradually through the joint preparation of both, teachers and students. In that case, the discussion content and students' learning would be more targeted and less off-topic. At the same time, a medical record-oriented teaching method has been developed and implemented in some colleges and universities during clinical practice, which has further extended the CBL teaching method. Upon the selection of clinical patients, students are encouraged to write clinical medical records with the content of medical records as the main line, decomposing the included knowledge points and carrying out targeted learning, and then discussing on each knowledge point as well as giving feedback to guide clinical practice $[8,9]$.

\subsection{Team-based learning (TBL)}

TBL is a new teaching model that has been reformed and innovated on the basis of PBL. It helps promote learners' teamwork spirit and emphasizes on human creativity, flexibility, and practical characteristics. It has changed the traditional way of teaching with teachers as the main body; rather, it emphasizes on studentoriented team learning and teachers' intensive teaching as a whole ${ }^{[10]}$. TBL focuses on the problem itself in the education process of the medical field to exercise students' independence, cultivate their ability to analyze and solve problems, as well as strengthen the team spirit and significance in clinical practice. It provides a foundation for cultivating doctors with a sense of teamwork, which is conducive to raising medical standards ${ }^{[11]}$. Several studies have affirmed the positive effect of TBL, but they have also pointed out that this teaching method has certain shortcomings, such as the difficulty of ensuring the enthusiasm of students with poor grades and peer pressure as a result of eugenics. Therefore, this teaching method still requires optimization ${ }^{[12]}$.

\section{Supplementary teaching methods}

Recently, with the progress of teaching reform, more and more colleges and universities have developed diversified and personalized teaching models based on the aforementioned teaching methods for clinical 
practice teaching.

\subsection{Standardized Patient (SP)}

SP refers to a healthy individual or a patient who has received training and can accurately represent the actual clinical problems of a patient. SPs are required to act as patients or as assessors or instructors. SPs generally do not exist as an independent teaching or assessment method but are usually introduced into assessments involving medical history inquiries or clinical examinations. In actual practice, some scholars have used SPs in PBLs and CBLs and found that this incorporation can effectively alleviate the difficulties of clinical probation caused by insufficient clinical case resources due to the increased protection awareness among patients. It can also effectively avoid moral and ethical issues involved in probation and internship, which is conducive to cultivating students' clinical practice and independent thinking skills ${ }^{[13-15]}$.

\subsection{Tutor system}

The undergraduate tutor system is a personalized practical teaching method that focuses on individual guidance and comprehensive quality training of students, which is a good supplement to traditional teaching in clinical practice. The tutor system can better cultivate the sense of identity and belonging among interns, thus motivating them to actively participate in and cooperate with various teaching work and daily clinical work of the tutors. The tutor system increases the frequency of students' contact with their tutors; in that way, the tutors would be able to gauge the interns' work, learning, and life status in real time as well as provide positive thought guidance, professional guidance, life guidance, and psychological counseling when necessary ${ }^{[16-18]}$.

\subsection{Application of information technology and internet}

Information technology and the internet have opened up a new field of clinical practice teaching. In traditional clinical practice teaching, teachers are usually teaching, while students just observe; this phenomenon leads to poor enthusiasm among students and often results in the inability to combine theory with practice; thus, the students may face difficulties in meeting the job competencies in the future. "Internet plus teaching" has played a role in supplementary teaching in clinical practice, especially during the COVID-19 pandemic. In order to reduce the risk of cluster infections on campus, universities have postponed the commencement of the 2020 spring semester, and online internships have become the teaching method of clinical practice in most colleges and universities. Some scholars have reported combining various online courses, such as massive open online courses (MOOCs), micro-classes, flipped classrooms, small private online courses (SPOC), and other teaching methods, such as PBL and TBL ${ }^{[19-21]}$, which would help cultivate students' autonomous learning ability and clinical reasoning ${ }^{[22,23]}$.

\section{Conclusion}

At present, medical education has introduced diversified teaching methods in clinical practice teaching, actively integrated courses, and achieved the purpose of improving students' clinical skills as well as their learning enthusiasm. However, the aforementioned teaching methods put forward higher requirements for teachers, thus requiring the establishment and improvement of corresponding teaching evaluation systems and implementation procedures. 


\section{Funding}

This study was supported by Heilongjiang Province Education Science “13th Five-Year Plan” 2020 Key Topics Project (Item number: GJB1320365).

\section{Disclosure statement}

The authors declare that there is no conflict of interest.

\section{References}

[1] Jiang S, Wang K, Jiang Y, et al., 2015, The Current Situation and Countermeasures of Medical Clinical Practice Teaching. Medicine and Philosophy (B), 36(01): 95-97.

[2] Shu T, 2008, Evidence-based Thinking and Clinical Practice Teaching. Chinese Journal of Social Medicine, 2008(01): 7-8.

[3] Lu S, Du J, Yi G, et al., 2020, Investigation and Research on the Status of Clinical Internship in Medical Colleges. Continue Medical Education, 34(04): 39-41.

[4] Yu X, Zhang G, Liu Z, et al., 2020, Discussion on the Application of PBL in Clinical Practice Teaching of Undergraduates. Shandong Education, 2020(05): 56-58.

[5] Yu X, Cao Y, Qiu L, 2019, Research on PBL Teaching Method Based on Oral Integration Course. Health Vocational Education, 37(10): 61-62.

[6] Pan J, Luo Z, Xue Q, et al., 2021, Application and Analysis of PBL Combined Translocation Teaching Method in Hematology Teaching Rounds. China Continuing Medical Education, 13(05): 21-24.

[7] Gong L, Zhu X, Wang P, et al., 2021, Talking about PBL Teaching Preparation. China Higher Medical Education, 2021(03): 118-119, 121.

[8] Ren C, He R, Liu S, et al., 2016, Analysis of the Effect of CBL Teaching Method in the Cultivation of Postgraduates' Clinical Ability. China Higher Medical Education, 2016(01): 125-126.

[9] Wang F, Fan Z, Wang Z, 2015, The Practical Experience of "Case-based" Teaching Method in Stomatology Teaching. Journal of Oral and Maxillofacial Surgery, 25(01): 69-71.

[10] Yang H, Chen T, Zhu X, et al., 2019, Research on the Practical Effect of PBL Teaching Model in the Teaching of Evidence-based Medicine. Journal of Wannan Medical College, 38(4): 391-395.

[11] Zhao N, He L, Liao L, et al., 2021, Application of TBL Teaching Method in the Experimental Course of Oral Implantology for Undergraduates. Medical Education Research and Practice, 29(02): 296-299.

[12] Li Y, Wu J, Long Q, et al., 2021, Investigation and Analysis of Student feedback on the Application of TBL Teaching Method in Medical Courses. China Continuing Medical Education, 13(14): 41-45.

[13] Du B, Zhong Z, Liu J, et al., 2020, Application Progress of PBL Combined with SP Teaching Method in Clinical Teaching. China Higher Medical Education, 2020(04): 79-80.

[14] Wu J, Xiu Z, Zhang J, et al., 2020, Application of PBL+CBL+TBL Combined with SP Teaching Method in the Standardized Training of Resident Doctors in the Practice Skills of Doctor-patient Communication. Modern Distance Education of Chinese Medicine, 18(04): 12-14.

[15] Qu Y, Ma X, Liu Y, et al., 2019, Application of SP Combined with PBL Teaching Mode in Clinical Practice of Eight-year Medical Students. China Medical Education Technology, 33(05): 607-609, 630.

[16] He X, Zhang H, Han J, et al., 2021, Investigation and Analysis of the Implementation of Scientific Research Tutor System for Clinical Medicine Undergraduates. Chinese Journal of Medical Education, 41(05): 438-442. 
[17] Li B, Su S, Fang C, et al., 2020, Research on the Application of Tutor System Teaching Mode in Clinical Practice of Hepatobiliary Surgery for Undergraduates. Modern Medicine and Health, 36(14): 2281-2283.

[18] Wang Q, Wang Q, Zhang R, et al., 2019, The Application of Tutor System Teaching Mode in Clinical Practice Teaching of Medical Imaging Undergraduates. Journal of Practical Medical Imaging, 20(02): 209-210.

[19] Lu Y, Zhang Z, Li J, et al., 2020, The Application of Micro-class Combined with PBL Teaching Method in Medical Imaging Teaching. China Continuing Medical Education, 12(30): 21-24.

[20] Xie H, Deng L, Pan A, et al., 2021, Application Research of Multi-dimensional Hybrid Teaching Mode Based on SPOC Platform in Ophthalmology Theory Teaching. China Higher Medical Education, 2021(01): 106-107.

[21] Yang H, Fu B, Pang L, et al., 2020, The Practical Application of Online TBL Teaching in the Teaching of Dental Undergraduates. China Higher Medical Education, 2020(10): 5, 85.

[22] Su Y, Xie Y, Qin J, et al., 2014, The Application of Mobile Smart Devices in Medical Clinical Practice. Modern Medicine and Health, 30(19): 3013-3014.

[23] Huang Z, Liu N, Tang X, et al., 2017, Development and Application of Oral Clinical Practice Teaching Client. China Medical Education Technology, 31(04): 422-425. 